OPEN ACCESS

Edited by:

Ana B. Bernardo,

University of Oviedo, Spain

Reviewed by:

Juland Dayo Salayo,

University of Santo Tomas, Philippines

Yovav Eshet,

Zefat Academic College, Israel

${ }^{*}$ Correspondence:

Krisztina Györi

gyorikrisztina97@gmail.com

Specialty section:

This article was submitted to

Higher Education,

a section of the journal

Frontiers in Education

Received: 12 November 2021

Accepted: 24 January 2022

Published: 11 February 2022

Citation:

Győri K and Pusztai G (2022)

Exploring the Relational

Embeddedness of Higher Educational

Students During Hungarian

Emergency Remote Teaching.

Front. Educ. 7:814168.

doi: 10.3389/feduc.2022.814168

\section{Exploring the Relational Embeddedness of Higher Educational Students During Hungarian Emergency Remote Teaching}

\author{
Krisztina Györi and Gabriella Pusztai
}

Center for Higher Educational Research and Development, Institute of Educational Science, MTA-DE-Parent-Teacher Cooperation Research Group, University of Debrecen, Debrecen, Hungary

In 2020, the researchers started studying with utmost haste the effect of the COVID-19 pandemic on teaching. The name of the form of teaching that came to be is disputed, neither the phrase of distance teaching nor digital teaching are professional enough. We use the term of emergency remote teaching (henceforth ERT), which appears in the scientific literature. This refers to the periodical diversion from the normal teaching, and to the emergency distancing in the teaching processes as well. In the present study, we focus on the alteration of student relationships and its correlation with higher educational efficiency because we see the reduction of student relationships as a discriminatory factor of this period. According to the previous results, the institutional embeddedness of students to be an indispensable condition of educational efficiency. In our study, we compared the states of the student relationships before and during the ERT. We hypothesise that the reduction of institutional relations caused by the epidemic is the cause for the student inefficiency, dissatisfaction, and distrust. Our questionnaire was filled by 677 students (172 males, 505 females) from 30 Hungarian higher education institutes altogether. Our results raise attention to the indispensable roles of instructors which are not in close relation to teaching. Furthermore, the results point that the weakening in the student relationships is in correlation with student persistence, student engagement, and institutional trust and satisfaction. According to the study, the reduction of student embeddedness had a negative impact on performance. A further conclusion is that all of this should be taken into consideration when working out a concept for a virtual university.

Keywords: COVID-19, emergency remote teaching, higher education, dropout, institutional embeddedness

\section{INTRODUCTION}

As a result of the expansion of higher education, as in other developed countries, the massification of higher education in Hungary has been increasing, leading to changes in the institutional structure and diversification of students (Kozma, 2004; Pusztai, 2015). Nevertheless, the number of students entering higher education in Hungary has stagnated in recent years (European Commission, 2019). It is, therefore, 
particularly worrying that the dropout rate of Hungarian students is higher than the OECD and EU averages and that $45 \%$ of the enrolled students do not graduate on time, while the average rate of students not finishing studies on time in OECD countries is around $30 \%$ (Varga, 2010). In addition, due to the pandemic erupted in 2019, the popularity of higher education in Hungary has further declined (Educational Authority, 2021). In the light of these data, achieving institutional embeddedness of higher education students in Hungary is of particular importance for their academic success. The pandemic has severely compromised the institutional embeddedness of students, as a new system of working without face-to-face contact, known as emergency remote teaching, has been introduced to avoid further infection (Hodges et al., 2020).

\section{Drop Out and Student Achievement}

In his work, Tinto (1975) found that students are more likely to drop out of their studies if they lack contacts and interactions within the institution. The poverty of students' institutional interactions weakens their academic effort, may weaken their belief in the successful attainment of their degree, and may reduce their academic achievement (Tinto, 1975; Astin, 1993).

Pusztai (2015) confirmed the research of Tinto (1975) and Astin (1993) on a Hungarian sample. Their research showed that students who are less embedded in the institution are more likely to drop out. The extent to which the students are embedded in their institution is a function of their intraorganisational relationships. Where students have quality relationships with fellow students (intragenerational relationships within the institution), they may find organisational and emotional support. In this way, partnerships can be created between them, which, in addition to friendship, can also serve as a source of knowledge. Tutors play a similarly indispensable role. In traditional models of higher education, the role of the lecturer was negligible in terms of embeddedness and persistence, but this role has now undergone a significant change. Research has shown that the instructor's interest toward the students, even when weak, can be decisive. If the students confronted are with a positive interest from their tutor, their trust in the tutor increases, which helps them complete their studies. When a tutor is also involved in talent management, it may increase the student's persistence and lead to scholarships, publications, or even job opportunities (Pusztai, 2015).

Studies often identify the risk of dropout with a lack of academic success. There are several ways to measure student achievement. In the present study, student achievement was measured through four efficacy predictors.

The first is persistence in higher education, which indicates student's motivation to study. For students, persistence means that they have succeeded in completing their studies or have conscious aspiration and conviction that they want to be able to complete their studies successfully (Tinto, 2017). Also an important factor of the student achievement is engagement, which is the time and effort students devote to educationally purposeful activities that contributes directly to the desired educational outcome ( $\mathrm{Hu}$ and Kuh, 2002) since real success in higher education can only be achieved if a person also makes an effort to obtain a degree (e.g., taking classes, taking notes, etc.). It is important to examine students' performance indicators related to the institution, including their trust and satisfaction with the institution. In the wake of Coleman (1990), trust is students' expectations of other students, faculty and university leaders to act and behave in a way that is beneficial to the students or at least not detrimental to them. Satisfaction is a shortterm students' disposition by subjective evaluation of educational experience, services and facilities (Elliott and Shin, 2002). These indicators have a determinant role in the dropout because the disillusionment with the institution and higher education can be a serious reason to suspend students' higher education studies (Pusztai et al., 2019).

The integration of students in an institutional social environment has a key role in the success (Tinto, 1993, 2006). Students, who cannot connect to the institution through their contacts, usually build up networks of contacts outside the institution, which can also contribute to persistence, in particular links with external activities such as volunteering or study-related employment (Kocsis and Pusztai, 2020; Pusztai et al., 2021). However, these friendships outside the institution (intragenerational relationship outside the institution) do not always increase students' persistence in their studies. In contrast, parents play an indispensable role in student achievement through their multifaceted and supportive influence on student persistence and engagement (Pusztai, 2019). It should be considered that both distance and remote education, in addition to their financial and practical benefits in pandemic-free times, may increase the risk of dropout for students by reducing school rituals, student and lecturer relationships and, thus, ties to the institution and higher education.

\section{Risk of Dropping Out From Higher Education During COVID}

One might think that the potentially globalising virtual social capital of the 21st century, which includes social networks among students, could make up for the lack of social contact caused by the pandemic (Arkhipova et al., 2020). Most of all, communities that existed before the ERT had the greatest impact on maintaining academic performance (Papp et al., 2021). Also, a study of ERT found that class attendance and academic activity did not decrease academic performance during ERT for students who had their relationships with faculty confirmed prior to the epidemic. The contact with the student's instructor was further strengthened by the fact that the instructors tried to connect with their students through various online platforms (Gares et al., 2020).

However, international researches in 2020 have shown that in forced remote education, impersonalisation is quickly followed by demotivation (Niemi and Kousa, 2020). Instructors who have been able to greatly reduce or prevent students' dropout anxiety and study problems with the help of a supportive emotional environment have proven to be extremely crucial to effectiveness during ERT (Steinberger et al., 2021). In addition, lecturers who may not be familiar with their own students and student's and lecturer's perceptions of learning are not the same also can 
increase the risk of dropping out (Al Shlowiy et al., 2021), these may be related to the trust and satisfaction in the institution that we want to measure. It was particularly demotivational for students to attend online classes without interactions, which they said greatly reduced their faith in completing their studies (Ghazi-Saidi et al., 2020).

In light of this, our research does not aim to review the methods and technologies of remote education. The main aim for our research was rather to examine the perceived lack of intraand intergenerational relationships often missing from remote education concerning the risk for dropout. It is legitimate to ask whether student achievement indicators deteriorate in relation to the loss of student contact during the epidemic, and we hypothesise that a decline in institutional embeddedness implies a loss of confidence in student progression and achievement.

\section{MATERIALS AND METHODS}

To answer our research question, we conducted a questionnaire survey during the first phase of remote education (May-June 2020). The questionnaire "Learning Alone" consisted of two modules. In the first unit, we retrospectively measured the experiences before the remote education, and in the second unit, we used the same questions to assess the respondents' assessment of their situation during remote education. Over a 6-week-long period, 677 students (172 men and 505 women) from a total of 30 higher education institutions in Hungary completed the questionnaire. Respondents studied in 14 training fields; $46 \%$ were at the beginning, $38 \%$ in the middle and $16 \%$ were at the end of their studies. The average age of respondents was $21.7(18-30)$ years. Most of the students' parents had a tertiary-level certificate $(46.7 \%)$, followed by those with a secondary educational certificate (40.8\%), while parents with primary education were the least represented among the respondents (12.4\%). The research questions were answered by using or improving certain blocks of the IESA (Effects of Institutional Integration on Student Achievement in Higher Education) and PERSIST questionnaires developed by CHERDHungary. The internal validity of the questionnaire is based on the fact that the CHERD research has been using almost the same questionnaire since 2001. In addition, the external validity of the questionnaire is based on the fact that age, sex, and training fields composition of the sample is almost exactly the same as the reference population from which the sample was taken. The self-developed questions, to which students could answer on a four-point scale. From the IESA questionnaire, we adapted the blocks on student network (Cronbach's alpha 0.798), while from the PERSIST questionnaire, we adapted the questions on achievement indicators, i.e., trust (Cronbach's alpha 0.851), satisfaction (Cronbach's alpha 0.923) and persistence and engagement (Cronbach's alpha 0.841). Finally, our questionnaire block on parental relationships also had a high reliability index (Cronbach's alpha 0.909). Thus, per structural unit, the

${ }^{1}$ Referring to the book of Robert Putnam entitled Bowling Alone: The Collapse and Revival of American Community (New York: Simon \& Schuster). respondent had to answer 68 questions during our questionnaire through 12 question blocks.

\section{RESULTS}

First, we examined changes in students' persistence $(p=0.000)$, engagement $(p=0.000)$, trust $(p=0.000)$ and satisfaction $(p=0.000)$ concerning higher education, which decreased significantly. The most significant decrease could have been experienced in academic engagement (62.8\% of students) This was followed by the proportion indicating a decrease in trust $(50.2 \%)$ and the proportion of students dissatisfied with the institution (50.2\%). A slightly lower proportion (40\%) was affected by a decrease in persistence in studies. Those who perceived a decrease in the former indicators were not over-represented in any groups created based on parental education (Figure 1).

The second step was to compare the structure and intensity of student relationships. We found that the relationship structure became significantly poorer everywhere except for parentstudent relationships. Intragenerational relationships declined the most, with contact weakening mainly with fellow students (59\%) (Figure 2).

The reduction of contacts affected all students equally, regardless of their social background. Since the average scores for academic persistence, academic activity, trust, and satisfaction showed significant differences between the two periods, it was justified to conduct correlation analyses.

Pearson correlation shows us, that change of student's relationships correlated with the achievement predictors. The change in persistence correlated with the change in intraorganisational intragenerational $(p=0.081)$, extraorganisational intragenerational $(p=0.131)$ and intergenerational $(p=0.160)$ relationships. The change in

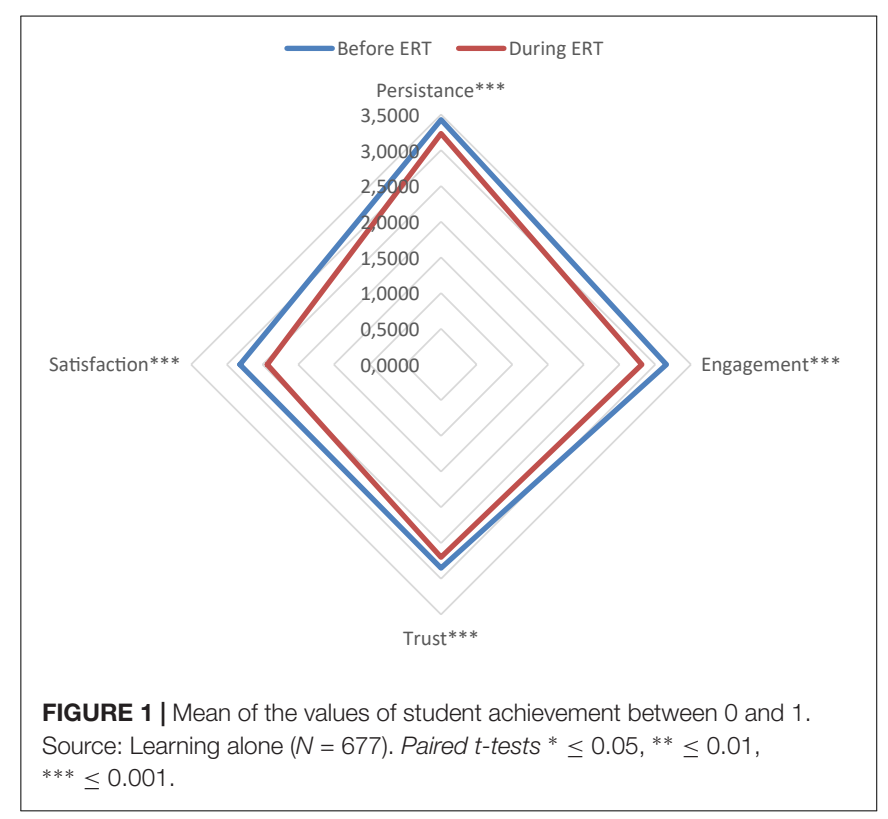




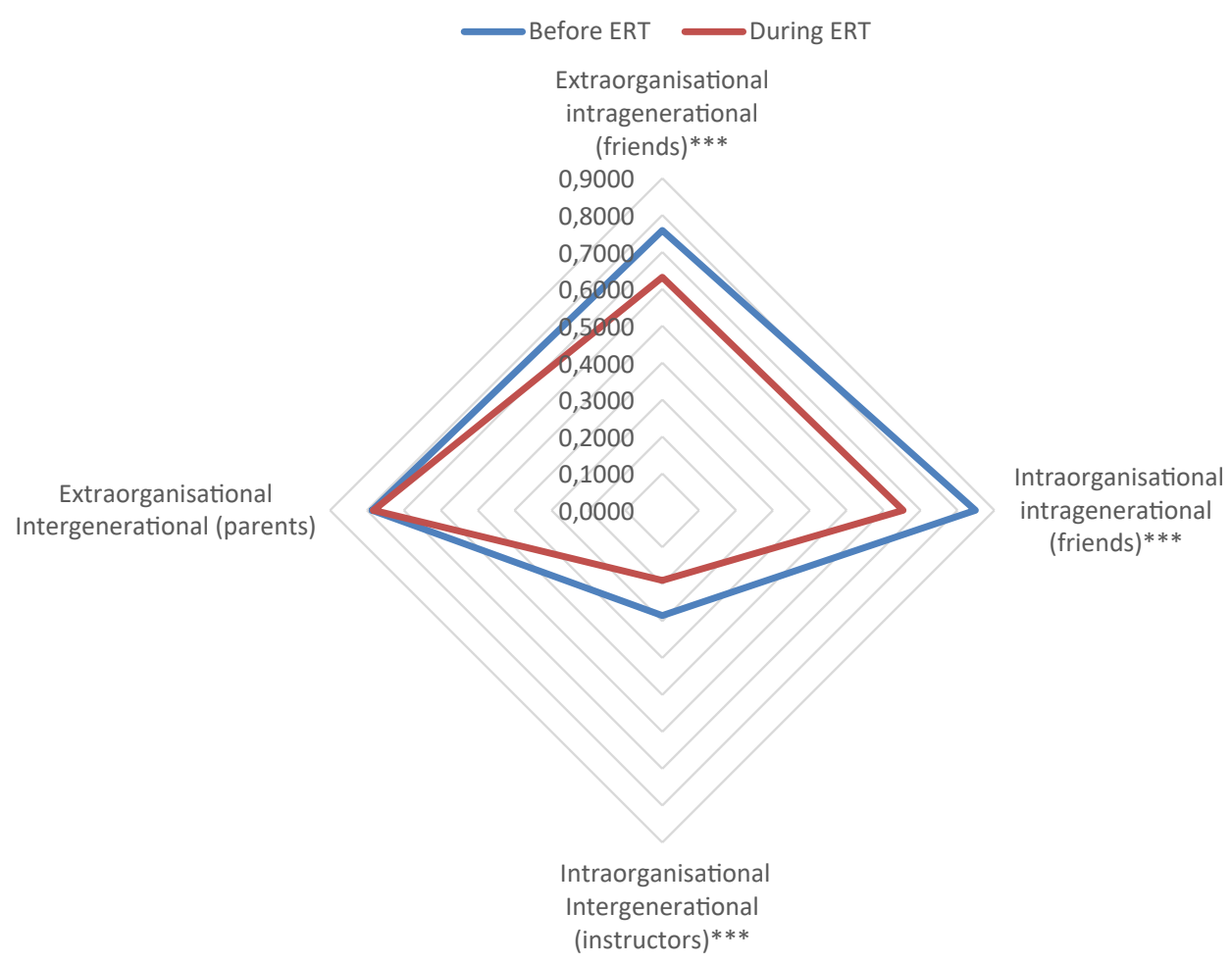

FIGURE 2 | Mean of the values of networks between 0 and 1. Source: Learning alone $(N=677)$. Paired t-tests $* \leq 0.05,{ }^{* *} \leq 0.01,{ }^{* * *} \leq 0.001$.

engagement correlated with the change in intraorganisational intragenerational $(p=0.189)$, extraorganisational intragenerational $(p=0.126)$ and intergenerational $(p=0.125)$ relationships. The change in trust correlated with the change in intraorganisational intragenerational $(p=0.108)$, extraorganisational intragenerational $(p=0.166)$ and intergenerational $(p=0.110)$ relationships. Finally, the change in satisfaction correlated with the change in intraorganisational intra- $(p=0.191)$ and intergenerational $(p=0.142)$, and extraorganisational intra- $(p=0.156)$ and intergenerational $(p=0.112)$ relationships. These results are presented in Table 1. It is important to note that our correlations were significant, however, can be characterised with weak intensity. Thus we continued our work with linear regression analysis.

Our linear regression analysis identified that the deterioration in the intraorganisational intragenerational relationships resulted in a decrease in both academic activity $(p=0.000)$ and satisfaction $(p=0.000)$. The deterioration in the relationship with instructors eventuated a significant decrease in satisfaction $(p=0.008)$. From the point of effectiveness, the decrease of the extraorganisational friendships proved to be decisive because the decrease experienced during the pandemic resulted in the deterioration in persistence $(p=0.006)$, trust $(p=0.001)$ and satisfaction $(p=0.088)$. Most people $(48.3 \%)$ had no change in their relationship with their parents. There was no change for any of the outcome predictors. Our results show that most students have moved back home to live with their parents, so their relationship has not deteriorated. However, in the case of students with a deterioration in parental relationships, a decrease in persistence $(p=0.002)$, engagement $(p=0.006)$ and satisfaction $(p=0.007)$ were also observed (Table 2$)$.

In the final step of the analysis, we examined which of the four dimensions of achievement (academic persistence, activity, satisfaction, trust), when aggregated and with a stronger than average chance of deterioration, was most affected by the weakening of the relationship resources while controlling for the other variables. With logistic regression analysis ${ }^{2}$, the strongest increase in the odds of student achievement deterioration was found to be the lack of peer relationships $($ Exp.B $=1.828$, $p=0.001$ ), followed by the loosening of parental relationships (Exp.B $=1.623, p=0.01$ ), and then the decrease in instructor contacts (Exp. $\mathrm{B}=1.473, p=0.022)$. When controlling for other variables, peer contacts outside the institution are not significant influential factors (Table 2).

This suggests that the influence of relationships with fellow students, parents and lecturers is independent and strong. This result further supports the thesis that a student well-embedded in the institution is, in fact, a student well-integrated in the student society. Parents are essential partners in education to maintain students' academic persistence and activity even during higher education. Furthermore, the contact with lecturers, further reduced by the context of remote teaching, could be solid support for the effectiveness of education.

\footnotetext{
${ }^{2}$ The value of the dependent variable was 1 if the deterioration was more severe than the average, i.e., if there was deterioration in at least two dimensions of effectiveness.
} 
TABLE 1 | Correlation of changing students' relationship with changing achievement predictors.

\begin{tabular}{|c|c|c|c|c|c|}
\hline & & Persistence & Engagement & Trust & Satisfaction \\
\hline \multirow[t]{2}{*}{ Intraorganisational } & Intragenerational (friends) & $0.081^{*}$ & $0.189^{\star \star}$ & $0.108^{\star \star}$ & $0.191^{\star \star}$ \\
\hline & Intergenerational (instructors) & NS & NS & NS & $0.142^{\star \star}$ \\
\hline \multirow[t]{2}{*}{ Extraorganisational } & Intragenerational (friends) & $0.131^{\star \star}$ & $0.126^{\star \star}$ & $0.166^{\star \star}$ & $0.156^{\star \star}$ \\
\hline & Intergenerational (parents) & $0.160^{\star \star}$ & $0.125^{\star \star}$ & $0.110^{\star \star}$ & $0.112^{\star \star}$ \\
\hline
\end{tabular}

Source: Learning alone $(N=677)$. Pearson correlation, ${ }^{*} \leq 0.05,{ }^{*} \leq 0.01$.

TABLE 2 | Connections of changing student's relationship with changing achievement predictors $(N=677)$.

\begin{tabular}{|c|c|c|c|c|c|c|c|c|}
\hline & \multicolumn{4}{|c|}{ Intraorganisational } & \multicolumn{4}{|c|}{ Extraorganisational } \\
\hline & \multicolumn{2}{|c|}{ Intra (friends) } & \multicolumn{2}{|c|}{ Inter (instructors) } & \multicolumn{2}{|c|}{ Intra (friends) } & \multicolumn{2}{|c|}{ Inter (parents) } \\
\hline & $\beta$ & Sig & $\beta$ & Sig & $\beta$ & Sig & $\beta$ & Sig \\
\hline Persistence & - & NS & - & NS & 0.113 & 0.006 & 0.120 & 0.002 \\
\hline Engagement & 0.164 & 0.000 & - & NS & - & NS & 0.105 & 0.006 \\
\hline Trust & - & NS & - & NS & 0,136 & 0.001 & - & NS \\
\hline Satisfaction & 0.143 & 0.000 & 0.102 & 0.008 & 0.088 & 0.028 & 0.101 & 0.007 \\
\hline
\end{tabular}

Source: Learning alone $(N=677)$. Linear regression.

\section{DISCUSSION}

Students' academic activity, persistence, trust and satisfaction with their studies have deteriorated consistently across all groups based on the parental educational level during the spring term of 2020. Apart from intergenerational relationships outside the institution (parent), all other relationship dimensions showed significant decreases concerning student contact.

Our study aimed to investigate how this change relates to changes in students' relationship networks with other people.

Particular attention was paid to changes in intragenerational relationships, as previous research has shown that these relationships are strongly associated with persistence and involvement in studies (Tinto, 1975; Astin, 1993; Pusztai, 2015). Our present data also confirmed this. The weakening of relationships with fellow students is most strongly associated with achievement: the reduction in friendships within the institution is accompanied by a reduction in academic activity and satisfaction.

The weakening of student- lecturer relationships was associated with a decrease in satisfaction. However, the relationship with lecturers was extremely low before ERT as well. Presumably, it can be due to the low involvement of Hungarian higher education lecturers in mentoring and tutoring students (Pusztai, 2015). Since our data suggest that the level of lecturerstudent contact was already low before remote education, its deterioration was associated with increasing mistrust. Among the actors in higher education institutions, generally, the instructors are the most trusted by students compared to rectors, deans, administrators and student representatives (Pusztai, 2015). This has also disappeared, and we consider this particularly dangerous as distrust is a characteristic of disenchantment with the institution, which is closely linked to an increase in the risk of dropping out (Pusztai et al., 2019). It was also typical that half of the students, who became more dissatisfied, experienced a decrease in their relationships with their lecturers. This confirms research that poor or declining relationships with instructors significantly contribute to student dissatisfaction (Pusztai, 2015).

There was no significant decrease in parental relationships, but those who had looser relationships with their parents also showed a decrease in persistence and activity. Our research confirms that the support of parents is not limited to financial factors, but their help as social and emotional support significantly contributes to their child's academic success, thus reducing the student's chances of dropping out (Pusztai, 2019).

Previous research measuring the impact of changes in intra-generational relationships on student persistence has reported mixed results as these student relationships usually encourage students to obtain a degree in some cases and the opposite in others (Pusztai, 2015; Kocsis and Pusztai, 2021; Pusztai et al., 2021). A decrease in relationships with peers outside the institution was also associated with decreased persistence, satisfaction and trust. However, unlike the other three relationship dimensions, this did not have a significant independent effect on the decrease in students' achievement. This partly confirms our hypothesis that a reduction in relationships with fellow students and lecturers increases the risk of inefficiency.

In summary, the risk of dropping out from tertiary education was increased during COVID. The lack of impersonality and fellow friends greatly reduces persistence and engagement. From our results, it can be assumed that neither the students nor the instructors were able to use the online space properly for communication (Ghazi-Saidi et al., 2020). Community organisation must also take place in the online space, and it is necessary to build an online platform where both lecturers and students can reach each other. In Hungary, the role of instructors in mentoring and tutoring is only significant for 
truly talented students, while policy measures help extremely disadvantaged students, leaving the widest range of students without institutional links to help them succeed. Consequently, to decrease the risk of dropping out, it would be important to draw the attention of instructors and education policymakers to the crowd left alone. During our research the largest available online student community was contacted. Thus, the conclusions drawn from the analysis cannot be generalised to the Hungarian student population. Although remote teaching caused by the pandemic can be seen as a much more rigorous distance education "experiment" than the average - exacerbated, of course, by the decline in extraorganisational contacts - this research has drawn attention to the fact that higher education has several additional functions besides knowledge transfer. Knowing this, it is important to be aware of the possible consequences of the lack of intraorganisational relationships in order to ensure that, in the future, alongside the increasing digitalisation of education, forms of work in higher education will be developed that can integrate the student into the social environment of the institution.

\section{CONCLUSION}

In our research, we aimed to examine the evolution of the relationship between higher education students during the pandemic period, after Tinto (1975) assumed a decrease in the qualitative and quantitative deterioration of relationships in performance predictors.

Results from our questionnaire were collected in the spring of 2020 suggest that the reduction of the students' relationship significantly correlated with the four outcome variables. The strength of intragenerational relationships within an institution is significantly correlated with changes in academic activity and satisfaction. Distance from instructors was associated with a rapid and sharp decline in satisfaction. Relationships with parents are strongly correlated with students' academic persistence and activity, and peer relationships outside the institution are associated with all dimensions except for academic activity. Based on our results, we can conclude that the decline in

\section{REFERENCES}

Al Shlowiy, A., Al-Hoorie, A. H., and Alharbi, M. (2021). Discrepancy between language learners and teachers concerns about emergency remote teaching. J. Comput. Assist. Learn. 37, 1528-1538. doi: 10.1111/jcal.12543

Arkhipova, V. A., Vasilyeva, L. G., Gurdzhiyan, V. L., Makarov, A. L., Mashkin, N. A., Nikitina, A. A., et al. (2020). Features of student virtual social capital: characteristics, opportunities and limits. Eurasian J. Biosci. 14, 3725-3729.

Astin, A. W. (1993). What Matters in College: Four Critical Years Revisited. San Francisco: Jossey-Bass.

Coleman, J. S. (1990). Foundations of Social Theory. Cambridge, MA: Harvard University Press.

Educational Authority (2021). Friss Statisztikák. Available online at: https://www.felvi.hu/felveteli/ponthatarok_statisztikak/friss_statisztikak/ WFrissStatisztikak/index.php/friss_statisztikak/ (accessed January 30, 2022).

Elliott, K. M., and Shin, D. (2002). Student satisfaction: an alternative approach to assessing this important concept. J. High. Educ. Policy Manag. 24, 197-209. doi: $10.1080 / 1360080022000013518$ student relationships radically increased the risk of dropping out during the epidemic. The greatest detrimental effect was found on the decline in student relationships, followed by parentlecturer relationships.

Our limitations are that we were not able to collect representative data during the pandemic, so our results can only be interpreted to a limited extent. It would be really useful to repeat our research to examine the extent to which students, who are already socialised online, differ from those who are socialised in attendance education and to consider the difficulty of socialising students entering higher education during COVID.

\section{DATA AVAILABILITY STATEMENT}

The raw data supporting the conclusions of this article will be made available by the authors, without undue reservation.

\section{ETHICS STATEMENT}

Ethical review and approval was not required for the study on human participants in accordance with the Local Legislation and Institutional Requirements. The patients/participants provided their written informed consent to participate in this study.

\section{AUTHOR CONTRIBUTIONS}

All authors listed have made a substantial, direct, and intellectual contribution to the work, and approved it for publication.

\section{FUNDING}

The research on which this manuscript is based has been implemented by the MTA-DE-Parent-Teacher Cooperation Research Group and with the support provided by the Scientific Foundations of Education Research Program of the Hungarian Academy of Sciences.

European Commission (2019). Eurostat. Available online at: http://appsso. eurostat.ec.europa.eu/nui/show.do?wai=true\&dataset=educ_uoe_enrt01 (accessed January 30, 2022).

Gares, S. L., Kariuki, J. K., and Rempel, B. P. (2020). CommUnity matters: student-instructor relationships foster student motivation and engagement in an emergency remote teaching environment. J. Chem. Educ. 97, 3332-3335. doi: 10.1021/acs.jchemed.0c0 0635

Ghazi-Saidi, L., Criffield, A., Kracl, C. L., McKelvey, M., Obasi, S. N., and $\mathrm{Vu}, \mathrm{P}$. (2020). Moving from face-to-face to remote instruction in a higher education institution during a pandemic: multiple case studies. Int. J. Technol. Educ. Sci. 4, 370-383. doi: 10.46328/ijtes.v4i4. 169

Hodges, C., Moore, S., Lockee, B., Trust, T., and Bond, A. (2020). The Differences Between Emergency Remote Teaching and Online Learning. Available online at: https://er.educause.edu/articles/2020/3/the-differencebetween-emergency-remote-teaching-and-online-learning (accessed January 30, 2022). 
Hu, S., and Kuh, G. D. (2002). Being (dis) engaged in educationally purposeful activities: the influences of student and institutional characteristics. Res. High. Educ. 43, 555-575. doi: 10.1023/A:1020114231387

Kocsis, Z., and Pusztai, G. (2020). Student employment as a possible factor of dropout. Acta Polytech. Hung. 17, 183-199. doi: 10.12700/APH.17.4.2020.4.10

Kocsis, Z., and Pusztai, G. (2021). A double road to success? impact of dual education on effectiveness. Res. Post-Compulsory Edu. 26, 164-188. doi: 10. 1080/13596748.2021.1909923

Kozma, T. (2004). Kié az egyetem?. Budapest: Új Mandátum Könyvkiadó.

Niemi, H. M., and Kousa, P. (2020). A case study of students' and teachers' perceptions in a Finnish high school during the COVID pandemic. Int. J. Technol. Educ. Sci. 4, 352-369. doi: 10.46328/ijtes.v4i4. 167

Papp, D., Gyõri, K., Kovács, K. E., and Csukonyi, C. (2021). The effects of video gaming on academic effectiveness of higher education students during emergency remote teaching. Hung. Educ. Res. J. doi: 10.1556/063.2021.00101

Pusztai, G. (2015). Pathways to Success in Higher Education. Frankfurt, Germany: Peter Lang Verlag. doi: 10.3726/978-3-653-05577-1

Pusztai, G. (2019). The role of intergenerational social capital in diminishing student attrition. J. Adult Learn. Knowl. Innov. 3, 20-26. doi: 10.1556/2059.02. 2018.04

Pusztai, G., Fényes, H., and Markos, V. (2021). The effect of volunteering and voluntary group membership on student's persistence. Heliyon 7:e07900. doi: 10.1016/j.heliyon.2021.e07900

Pusztai, G., Fenyes, H., Szigeti, F., and Pallay, K. (2019). Dropped-out students and the decision to drop-out in Hungary. Cent. European J. Educ. Res. 1, 31-40. doi: 10.37441/CEJER/2019/1/1/3341

Steinberger, P., Eshet, Y., and Grinautsky, K. (2021). No anxious student is left behind: statistics anxiety, personality traits, and academic dishonesty- lessons from COVID-19. Sustainability 13:4762. doi: 10.3390/su1309 4762

Tinto, V. (1975). Dropout from higher education: a theoretical synthesis of recent research. Rev. Educ. Res. 45, 89-125. doi: 10.3102/00346543045001089

Tinto, V. (1993). Leaving College: Rethinking the Causes and Cures of Student Attrition. Chicago, IL: University of Chicago Press.

Tinto, V. (2006). Research and practice of student retention: what next? J. Coll. Stud. Ret. 8, 1-19. doi: 10.2190/4YNU-4TMB-22DJ-AN4W

Tinto, V. (2017). Reflections on student persistence. Stud. Success 8, 1-9. doi: 10.5204/ssj.v8i2.376

Varga, J. (2010). Mennyit ér a diploma a kétezres években Magyarországon? Educatio 12, 370-383.

Conflict of Interest: The authors declare that the research was conducted in the absence of any commercial or financial relationships that could be construed as a potential conflict of interest.

Publisher's Note: All claims expressed in this article are solely those of the authors and do not necessarily represent those of their affiliated organizations, or those of the publisher, the editors and the reviewers. Any product that may be evaluated in this article, or claim that may be made by its manufacturer, is not guaranteed or endorsed by the publisher.

Copyright (C) 2022 Györi and Pusztai. This is an open-access article distributed under the terms of the Creative Commons Attribution License (CC BY). The use, distribution or reproduction in other forums is permitted, provided the original author(s) and the copyright owner(s) are credited and that the original publication in this journal is cited, in accordance with accepted academic practice. No use, distribution or reproduction is permitted which does not comply with these terms. 